Acta Universitatis Wratislaviensis • No 3869

Literatura i Kultura Popularna XXIV, Wrocław 2018

DOI: $10.19195 / 0867-7441.24 .14$

\author{
Katarzyna Marak \\ ORCID: 0000-0003-4073-8889 \\ Nicolaus Copernicus University in Toruń \\ Nelly Strehlau \\ ORCID: 0000-0001-7670-7860 \\ Nicolaus Copernicus University in Toruń
}

\title{
Thanatomorphose and Contracted: Feminine body and sexuality in horror and the horror of feminine body and sexuality
} decay

Keywords: femininity, objectification, femininity in horror, female sexuality, death,

Słowa kluczowe: kobiecość, uprzedmiotowienie, kobiecość w fantastyce grozy, kobieca seksualność, śmierć, rozkład

The body in horror fiction is, as Jack Morgan argues, "mystery incarnate" in itself; "the occasion of birth, life, sexuality, and death as well as of all disease, nightmare, and terror". ${ }^{1}$ While focusing mainly on death, horror texts tend to address as many of those as possible. Horror fiction authors connect death with sexuality, disease and all manner of body horror in most imaginative ways, making use of not only the natural fear of death shared by virtually all audiences, but also the abject nature of the dead body and everything related to it, so prominent in Western culture.

The recognition of the dead body as abject is a relatively new attitude. Around the end of the 18th century Western culture underwent a radical and significant change in the perception of the dead, which can be observed in funerary practices and rituals of that time; this change consisted in "disguising evidence of bodily

\footnotetext{
${ }^{1}$ J. Morgan, The Biology of Horror: Gothic Literature and Film, Carbondale 2002, p. 22.
} 
decay, beautifying the dead body and mitigating the finality of death through metaphors of sleep and reunion. It appears to be related to the emergence of a strong distaste for any reminder of bodily mortality, particularly the processes of postmortem decay". ${ }^{2}$ Putrefaction and disintegration, as "gruesome implications of human mortality", played out so graphically in horror fiction, are indeed more disturbing than the abstract concept of death, or the "neat term" itself. ${ }^{3}$ Death and decay are in fact separate matters: death, understood not as the process of dying, but arbitrary transition from being alive to being no longer alive, is swift: it is a point, a boundary, the ultimate end. Decay, on the other hand, is a process with no discernible end, beyond control and impossible to stop or to sanitize, ugly and unpleasant. This process is what Western culture tends to hide and reject, and what horror fiction frequently strives to emphasize for the desired effect.

While decay - as well as disease - is featured in horror fiction on numerous occasions, it is merely a symbolic realization of a repulsive subject, and not an instance of addressing repulsive subject matter; no sane person, as Morgan argues, is drawn to real world instances of rot and putrefaction. ${ }^{4}$ And yet the "intense preoccupation with the body and its propensity to corruption by disease, and the horror of physical decay after death" is prevalent in the horror genre, and earlier persisted in literature and in art as far back as from the 15th century. ${ }^{5}$ Disease and decay, although firmly separated by the impassable (apart from rare medical circumstances) line drawn by death, are closely connected in the human mind. "Fear of disease hidden in the body", as Catherine Belling points out, is inseparable from "fear of the horrific object the body will become, once it has succumbed to disease". 6 Similarly, the body is destined to become the horrific object after death. And yet, interestingly enough, despite the fact that a plethora of horror texts concerning bodily horror focus on dying, few supernatural horror narratives employ disease and/or decay as their sole or even primary point of focus. Apart from zombie narratives, in which explicit signs of decomposition are used to emphasize the interstitial dead/alive nature of the undead monster, the majority of horror texts focus on death itself as the ultimate, most horrific concept; the repulsive dead body — horrific object — appears only to evoke disgust and shock in the audience. Rarely do horror texts tackle the idea of becoming that horrific object. This paper deals with two horror films that address this scenario. Both Éric Falardeau's Thanatomorphose (2012) and Eric England's Contracted (2013) construct the horror around the repulsive, horrifying putrefaction, weaving

${ }^{2}$ Y. Hamilakis, M. Pluciennik, S. Tarlow, Thinking Through the Body: Archaeologies of Corporeality, New York 2002, p. 94.

3 J. Morgan, op. cit., p. 14.

4 Ibid., p. 17.

${ }^{5}$ S. Hatty, J. Hatty, The Disordered Body Epidemic Disease and Cultural Transformation, Albany 1999, p. 98.

${ }^{6}$ C. Belling, A Condition of Doubt: The Meanings of Hypochondria, New York 2012, p. 175. 
narratives about the transformation into the abject - a drawn-out process, rather than a momentary transition from subject to object of abjection - omitting death as ontological and temporal occurrence in their premise and storylines, instead offering a spectacle where decomposition precedes or substitutes for, rather than follows the ultimate act of dying. Both Thanatomorphose and Contracted deal with shock and horror surrounding rot, disfigurement and disintegration of the body. Their respective stories concern young women struck by a sudden, inexplicable affliction that causes their bodies to degenerate. In both cases the process is gradual and apparently unstoppable. However, in spite of these evident similarities, the texts portray quite different images of women and their sexuality, feminine aesthetics and agency, and the delicate balance between being the victim and being the aggressor. The purpose of this paper is to demonstrate how the two texts, although belonging to the same genre and using similar imagery and themes of bodily decay and sexuality, construct two fundamentally antithetic disparate representations of womanhood in the context of Western cultural framework. ${ }^{7}$

The first of the films, Thanatomorphose, makes use of a small cast and a confined, small-scale set to make its point. The film focuses on the character of a lonely young woman, Laura, living alone in a rented apartment. Little is known about Laura apart from the fact that she is an artist, and that she is stuck in an abusive relationship with a man who clearly neither shares her interests nor cares about her feelings. Whether she has friends or any family, remains unknown. As the story moves forward, Laura begins to suffer from a mysterious affliction which slowly causes her body to rot from inside out.

Falardeau's text begins, significantly, with sex — at first sensual, then faster and more vehement, perhaps even violent. In the opening scenes that follow, the audience sees Laura and her boyfriend walking around Laura's apartment naked. The nakedness is no longer sexual, but serves as a reminder that people have bodies and how those bodies are supposed to look and work - if injured, they no longer function properly and cannot be relied on. The explicit exposition also establishes the aesthetic frame for the narrative: Laura is constructed as a woman, both in terms of her looks and her sexuality, but she is neither idealized nor objectified; she wears glasses and hardly any make-up, her hair is plain and not styled, and her body shape is ordinary. To the audience, Laura is therefore more identifiable and less objectifiable. The fact that she is an artist additionally invokes aesthetics, but again, it is the functionality of the body that is actually at stake. As the putrefaction gradually destroys her body, her surroundings (her house, her dreamscapes) also decay and fall apart; tackling the environment and reality becomes increasingly difficult. ${ }^{8}$

\footnotetext{
${ }^{7}$ Issues such as the tradition of body-horror subgenre and genre deconstruction lie outside the scope of this article due to obvious length limits.

${ }^{8}$ It is, however, worth noting that initially, even in spite of the gruesome symptoms noticeable to both her and the audience, she appears to remain attractive to others within the narrative, as evidenced by the scene in which her neighbour accepts her sexual advances.
} 
The pivotal point of Thanatomorphose as a horror narrative, i.e. the rot, is represented in the film with all the repulsive details, but with little emphasis on shock delivery. The origin of the rot is unknown and never explained, although it is presumably related to Laura's recurring dreams that feature death and decomposition. Laura's reaction to the rot and the manner in which she copes with it are the driving forces of the story. As she becomes increasingly weak and unable to move at times, her skin bruising and breaking, Laura is at first anxious, and then understandably scared; she seems unwell but attempts to brave it out. With little interaction with the outside world, she is in fact alone with her problem, and her psychological state is what the audience is tuned to. Unable to guess the origin, the nature, or the ultimate conclusion of the mysterious affliction, Laura feels miserable; her fear and loneliness descend into panic and despair, which in turn spiral into fury and, eventually, insanity, as her still functioning mind is trapped within the hideous, putrefying shell that is falling apart. The rot progresses slowly, from within, without any particular order; the narrative constructs it as highly organic - it starts internally, inducing organ failures which only later manifest as bruises and degenerated skin. Inexplicable and supernatural, for Laura the rot represents literal and symbolic disintegration not only of her body, but of her life. The ultimate end of the rot, and Laura's destiny, is annihilation - absolute, complete decomposition into nothing and nothingness, with the mind and awareness intact and present until the body ceases to exist.

Contracted also focuses on a single female character, although there are other woman characters who play important roles in the story. The protagonist of England's text, Samantha, is, just like Laura, a young woman in an abusive relationship. Samantha's love interest is an older woman who is only outwardly, not emotionally involved in their affair. Torn between a friend with ulterior motifs and a judgemental mother who accepts neither her life choices nor her sexuality, unable to fulfil her dreams as an aspiring botanist, Samantha is - just like Laura lost and alone. It is important to note, however, that the presence of friends and clear goals in Contracted establishes a world less dream-like and abstract and more literal and identifiable than the one in Thanatomorphose.

Just like Thanatomorphose, Contracted also begins with a depiction of sexual contact, but of a much more sinister character: the audience first witnesses an act of necrophilia, and then (date) rape, as a stranger, who later functions in the narrative only under the nickname "BJ", drugs Samantha's drink and takes her to his car. In contrast to the manner in which Laura is introduced in the opening scenes of Thanatomorphose, England's text puts emphasis on Samantha's visual attractiveness, as she is wearing pretty clothes and evening make-up. This is significant insofar that the attire - as well as the use of the drug — gives the visual illusion of casual, consensual encounter, which in turn paves the way for the stereotypical, shame-based angle of portraying female sexuality employed in Contracted.

Samantha, in contrast to the protagonist of Thanatomorphose, is clearly a product of the world of mainstream, commerce-driven aesthetics: she does 
not wear glasses, her hair is long and well groomed, her make-up flawless, and her body, clothed in flattering clothes, is slim and shapely, although the audience never witnesses her taking care of any of those things. Samantha simply appears on the screen, beautiful - in contrast to Laura, who engages in various grooming activities, but for her own satisfaction rather than for some specific aesthetic effect. What is both interesting and significant, Samantha is arguably depicted as a downright unlikeable person, which is a rather peculiar strategy as far as horror formula is concerned, since the success of a horror text tends to depend largely on the audience's emotional investment in the emotional state of the character and their well-being. Even her out-of-control, maniacal aggression at the end is different from Laura's rage. Samantha does not seem to have descended into insanity in the same fashion as Laura - the audience is rather given to understand that it is her personality that drives her to commit all the deeds she does.

Although the two films are often placed side by side by Internet users who have seen the texts, the extent, nature and the role of the seemingly identical horror factor are different in the respective storylines. Contracted offers the audience a speculative explanation of the origin of the rot - it is an STI-like infection that the protagonist contracts during her brief non-consensual sexual encounter with a stranger. Samantha does not know the man who infected her, neither does she understand the precise nature of the affliction, but she knows very well where and when it came from. At first she experiences alarm and later - what is more important in the context of the portrayal of female sexuality in the film - shame, since she is convinced she has contracted a sexually transmitted infection. Those feelings transform into fear and denial, then aggression and despair; ultimately Samantha descends into savage destructiveness, which is not the result of the rot, like it is the case with Laura, but another symptom of it. Until her last lucid moments, Samantha is plagued by the feeling of guilt and remorse; because she went to the party and got drunk, and ingested the date rape drug - however unknowingly and unwillingly - her situation is socially and conventionally constructed as her responsibility. In Contracted, the protagonist is not only the victim of the rot - she is constructed as being partially responsible for it. ${ }^{9}$ It is, therefore, all the more important that the rot represents aesthetic punishment and is constructed as primarily external: it progresses in no logical order from one body part associated with attractiveness/sex to another as it affects Samantha's face, her hair, the teeth, the eyes, the lips, and, most importantly, the vagina and the uterus. ${ }^{10}$

9 This reading of the narrative as assigning partial blame for her condition to the victim of rape is supported by the reactions of both the protagonist (who experiences shame and whose shame is never contradicted as unfounded) and other characters, such as Samantha's friend, her former lover and her doctor, all of whom appear to be disgusted by Samantha's condition and assign to her the responsibility for the sexual encounter.

${ }^{10}$ As Barbara Creed rightly points out, it may be difficult to avoid defining female sexuality as inherently abject when portraying a woman's monstrosity through the abjection based in her re- 
In contrast to Laura, Samantha is neither weak nor disoriented, but rather highly strung and agitated. Yet, even at full control of her body she cannot keep herself from falling apart, literally, piece by piece. Biological in its nature, infectious and shameful, the rot in Contracted represents a stigmatizing degeneration of the body as well as life. Its ultimate end is dehumanisation - the irreversible dissolution of the mind and loss of human identity.

The disparate approaches to the rot actually stand for disparate representations of women and femininity. In Thanatomorphose, the horror is created around the feminine, whereas in Contracted the horror is created by the feminine. ${ }^{11}$ While in Thanatomorphose the rot is introduced and presented as a magical, unforeseeable and undeserved calamity the protagonist is suffering, in Contracted the rot is constructed as a punishment for a sexual act (even if not consensual) and aimed at everything physical that makes a woman a woman. Contracted exaggerates and renders repulsive everything that is related to a woman's biology - both reproductive and sexual. Although it is Samantha who contracted the rot from the stranger through no fault of her own, England's text paints a horrifying image of the female body as a Petri dish of vile, putrefying bodily hazards, a depiction of "devalued difference" that, as Rosi Braidotti underlines, is "a constant in Western thought", which sees women, and specifically their bodies, as "unholy, disorderly, subhuman and unsightly" (emphasis added). ${ }^{12}$ Thanatomorphose does focus on the sexual aspect of body and rot as well, but in Falardeau's text this is used as a metaphor of Laura's place in the eyes and life of men - this can be observed in one of the dream sequences at the end of chapter 5, where her organs (after having been cut out in an earlier, highly suggestively edited scene) are fed to naked, caged men who objectify her in her real life. This aims more at illustrating Laura's subconscious understanding of the way she is treated and perceived than addressing her actual sexuality and attractiveness.

This difference in approach is visible even in the very basic aspects of the story's premise, specifically the target point of art-horror. Thanatomorphose constructs its horror as the horror of an individual and the horror of the mind: throughout the majority of the film Laura is alone in her house, where there is no-one to see her - which means that there is no-one to be shocked, to judge or to be disgusted. What Laura must face - alone - is the deterioration of her body, the growing incapacity and the end of her existence, not only as she knew it, but in

productive organs; compare B. Creed, The Monstrous-Feminine: Film, Feminism, Psychoanalysis, London-New York 2007, pp. 2, 151-152.

${ }^{11}$ A detailed and germinal discussion of feminine monstrosity can be found in B. Creed's aforementioned work (The Monstrous-Feminine...); nevertheless, Creed considers women as monsters as opposed to women as victims, whereas the films under discussion are also notable for (more or less successfully) collapsing that boundary so that their protagonists fulfil both roles.

12 R. Braidotti, Nomadic Subjects: Embodiment and Sexual Difference in Contemporary Feminist Theory, New York 1994, p. 80. 
general. In this sense, Thanatomorphose makes use of organic horror to make a point about a more existential matter. Contracted, on the other hand, constructs its horror as a social horror. Samantha is infected with the rot by another person; ${ }^{13}$ furthermore, she must deal not only with the rot, but with people's reactions, ideas, assumptions and repulsion. The people surrounding her - including her friend, her mother and her boss - are less concerned and more horrified and unpleasant, or even judgemental of the changes (Alice refers to Samantha's bloodshot eye as "super-gross", and Samantha's mother assumes that the damage to Samantha's body is done by Samantha herself). In terms of horror narrative, Thanatomorphose focuses on Laura's horror at her own body, and Contracted focuses on horror evoked by Samantha's body in others (Samantha herself seems to be more frustrated and upset than genuinely horrified), which in turns translates to horror that the audience is supposed to experience for the character or together with the character, and not, like in Contracted, the horror the audience experiences at the character.

The most significant, if not defining, aspect of Contracted, in comparison with Thanatomorphose, is the manner in which it creates its horror around the female/ feminine body. The associations between bodily femininity and horror were perhaps most comprehensively covered by Julia Kristeva in her book Powers of Horror. On its pages, Kristeva undertakes a psychoanalytic analysis of the notion of the abject - that which is "improper/unclean", associated with the "uncann[y]", a source of loathing and fascination that Kristeva connects with boundaries and that which "encroached upon [them]"; abjection is thus the subject's reaction to the danger of one's identity being subsumed and serves as a self-constituting act: it is through this rejection of the Other that "[self] give[s] birth to [it]self". ${ }^{14}$

However, it should be noted, as Braidotti rightly brings to attention, that for Kristeva, and within the Western cultural framework in general, it is ultimately femininity and the female body that constitute a primary source of abjection, as "the maternal body [is] the site of the origin of life and consequently also of the insertion into mortality and death [...] the mother's body [...] is attractive and repulsive" 15 at the same time. Thus, female sexuality and everything that is associated with its reproductive function - be it menstruation or female sexual organs - may be seen as particularly fitting (though also dangerously regressive)

${ }^{13}$ In contrast, as the article addresses in more detail later on, the source of Samantha's infection - her rapist - is not shown to be suffering from similar symptoms, and while his necrophilia is presumably the cause of the infection, his body is not subject to any scrutiny, which only partly can be explained by the relatively short time devoted to the character within the film.

14 J. Kristeva, Powers of Horror: An Essay on Abjection, New York 1982, pp. 2-3.

15 R. Braidotti, op. cit., p. 81. Significantly, while for Braidotti this description of feminine monstrosity is a point of departure for transgressive and productive notion of "epistemic nomadism" that would enable the re-configuration of (woman's) subjectivity (compare ibid., pp. 93-94), Contracted only reproduces femininity as different and as monstrous. 
subjects for exploration in relation to horror and death, as well as bodily decay, at least within the aforementioned cultural framework.

Accordingly, the very first thing Samantha notices where her affliction is concerned is the bleeding, which she initially — and significantly — attributes to her menstrual cycle; during the course of the story, the bleeding intensifies and spirals out of control, providing a horrific, monstrous depiction of the woman's bodily functions. Almost at the same time Samantha notices on her abdomen what she takes for a rash, which prompts her to see a doctor. The doctor implies that she most probably has an STI - a diagnosis (judgement) Samantha accepts without questions. At this point the narrative establishes its peculiar perspective, which relies on a strange mixture of shame and revulsion. Samantha is driven by shame and ashamed of her body. The first places to be affected by the rot are her genital area, representing her sexuality, and her face, which represents her physical attractiveness. Samantha quickly becomes disfigured in the perception of the people around her as her eyes become grotesquely bloodshot, her teeth and hair begin falling out, and her skin is covered with repulsive lesions. The greatest emphasis, however, is placed on the changes occurring in her vagina - and, presumably, the uterus. In contrast to Laura, who seems to be devoured by the rot from inside out at a more or less steady pace, with no body part degenerating faster than others, Samantha appears to be losing her integrity the fastest around her genital area. From the start, apart from the heavy, unnatural bleeding, she suffers from soreness, unpleasant smell and tremendous pain; this demonizing representation of the vagina culminates in a profoundly disturbing scene when Riley, a man who has been shown to have an interest in Samantha, attempts to have sex with her, only to discover that her vagina is already putrefying and filled with maggots. This both concludes and expands the notion of the horror of the female body. On the one hand, Samantha is associated with death and infertility on multiple levels, both symbolically and literally — as a menstruating (and therefore non-pregnant) woman and as a woman rejecting intercourse with men, she is unable to give or even support life; even her orchids, previously a source of her pride, wither when exposed to her proximity; ${ }^{16}$ thus, everything she touches becomes sick and dies: she becomes a living corpse, "death infecting life". ${ }^{17}$ On the other hand, the maggots swarming out of her vagina connote a twisted image of fertility: the

${ }^{16}$ Significantly, the orchids — frequently used as a symbol of female sexuality — have an additional meaning as another illustration of Samantha's obsession with surfaces, further bringing to the narrative forefront the subject of the aesthetic function rather than functionality. Moreover, they provide an occasion for the film to question Samantha's mental state, as she may seem to be cognitively affected by her infection; therefore, she is unable to reconcile herself with the fact that her disease has spread to the orchids when she insists on entering a botanical competition with flowers that are already decaying.

17 J. Kristeva, op. cit., p. 4. 
decaying corpse capable of "giving birth" to maggots. ${ }^{18}$ The concept of vaginal maggots is both a monstrous rendering and a caricature of female fertility and sexuality, where the female reproductive system is twisted into a revolting monstrosity spewing pollution and death, a figure of Kristevan abjection. The fact that this is discovered by Riley during the sexual contact initiated by Samantha further implies that female pleasure is monstrous, disgusting and rotten, and wreaks destruction.

Samantha's behaviour also plays an important part in this perspective. She is secretive and attempts to hide her symptoms from everyone; this results partly from her previously mentioned shame and guilt, and partly from her fear that Nik$\mathrm{ki}$, the woman she is in love with and who is unilaterally ending their relationship, might find out about her being assaulted and react to it unfavourably. It apparently never occurs to her - or for some reasons she decides not to - to tell anyone that she was raped, but instead acts as if the encounter was a decision for whose consequences she should now bear responsibility - arguably, her ambivalence may be examined as part of a larger narrative ambivalence, as even though the act doubtlessly meets most legal definitions of rape, the characters appear to perceive it as proof of Samantha's bisexuality, indecisiveness or infidelity. This approach echoes the popular if widely criticized notions of date rape not being a serious crime or a crime at all; as Katie Roiphe proclaimed in her frequently-quoted, controversial 1993 book, The Morning After: Sex, Fear, and Feminism "someone's rape may be another person's bad night" 19 — the characters evince a similar attitude, which may explain Samantha's own confusion and inability to locate blame outside of herself.

Every time something terrifying happens to Samantha's body, she reacts with panicked, frantic attempts to cover it up - specifically, to clean it up so as to maintain an aesthetically pleasing surface. There are a couple of scenes of Samantha frantically cleaning up after her body literally falls apart, as if she were more ashamed than scared. It is also worth noting that Samantha has a (feminine) history of self-harm behaviour, which fits the overall shame/guilt-driven focus of the story. In contrast, Laura, who also has a history of allowing her boyfriend to harm her, seems more driven by the growing fear that her body will not work. In spite of her being an artist, and thus ostensibly concerned with aesthetics, Laura appears to approach her own body as a tool of her work (significantly, her medium is

18 C. Bynum, The Resurrection of the Body in Western Christianity, 200-1336, New York 1995, p. 78.

${ }^{19}$ K. Roiphe, The Morning After: Sex, Fear, and Feminism, London 1993, p. 54; the quote also appears, albeit with slight changes, in an earlier version of the chapter entitled "Date rape's other victim", published by The New York Times Magazine in June 1993, available online on the magazine's website, http://www.nytimes.com/1993/06/13/magazine/date-rape-s-other-victim.htm1?pagewanted=all (accessed: 5.11 .2014$)$. 
sculpture, and thus three-dimensional and tactile) rather than an object of others' gaze.

Both in Thanatomorphose and Contracted, sexuality seems to be connected with violence and danger - it is implied that Laura is being abused by her boyfriend whereas Samantha is raped; furthermore, in both films the conditions seem to prompt the main characters to seek out sexual partners, to whom they may presumably be transmitted, or whose continued attraction to the protagonists would allow the women to feel reassured. However, as it has previously been stated, none of the men exposed to the condition, or even acting as its vectors as in the case of Samantha's abuser, are visibly affected by the symptoms. Arguably, while Samantha's actions following her having been infected with the mysterious STI imply the possibility that the disease in Contracted causes hypersexuality in her, its effect on $\mathrm{BJ}$ is doubtful, as his transgressive sexual behaviour predates the disease and is in fact its likely cause. Thus, while the connection between sexuality, violence and the disease is present in both films, in both it is only women in whom all three become associated with bodily decay and putrefaction.

As Morgan argues, horror texts, whether literary or cinematic, tend to address "organic states of siege". ${ }^{20}$ Usually the horror comes from the outside: there is an attacker or some other sort of physical danger that the living protagonist tries to escape, and the ultimate threat is death. In Thanatomorphose and Contracted, the threat invades from the inside. The characters cannot run from it, since the body is inescapable and obligatory for a person to live. While Samantha runs from death (until the very end it could be argued she is simply very, very sick), Laura discovers that she is, in a sense, already dead: for ultimately she is a corpse, only a conscious one. While Samantha experiences the horror of being undead - the horror related to one of the "principal archetypes for fear of death: [...] reanimation and the need to feed", ${ }^{21}$ which conveys the two most vivid fears regarding the biological, organic nature of death, i.e. the fear of ceasing to be, but also the fear of being unable to die, ${ }^{22}$ Laura embodies the fear of bearing conscious witness to the breakdown of their bodily integrity without the blissful oblivion. As Kristeva points out, a decaying, lifeless body is a "body without soul, a non-body, disquieting matter". ${ }^{23}$ Samantha and Laura, however, are not lifeless; they are decaying, but they are not without a soul. The horror concerns not death, but the fear of being unable to break free/be set free from the decomposing shell.

Catherine Belling states that "we all have it in us to become a hideous corpse". ${ }^{24}$ Thanatomorphose and Contracted explore this idea, adding a broader

${ }^{20}$ J. Morgan, op. cit., p. 18.

${ }^{21}$ D. Cowan, Sacred Terror: Religion and Horror on the Silver Screen, Texas 2008, p. 126.

22 As pointed out in Celebrations of Death: The Anthropology of Mortuary Ritual by P. Metcalf, R. Huntington, New York 1991, p. 196.

23 J. Kristeva, op. cit., p. 109.

${ }^{24}$ C. Belling, op. cit., p. 176. 
perspective of womanhood. In culture and fiction, women's bodies tend to be closely linked with notions of sex, sin and decay. ${ }^{25}$ Whereas Thanatomorphose focuses on sex and decay, and their relation to the woman's mind, Contracted chooses to associate the female body with the arbitrary notions of sin, shame and pollution. Although seemingly similar, the texts offer vastly different representations of women, women's bodies, and the relationship between the two.

\section{Bibliography}

Belling C., A Condition of Doubt: The Meanings of Hypochondria, Oxford University Press, New York 2012.

Braidotti R., Nomadic Subjects: Embodiment and Sexual Difference in Contemporary Feminist Theory, Columbia University Press, New York 1994.

Bynum C., The Resurrection of the Body in Western Christianity, 200-1336, Columbia University Press, New York 1995.

Cowan D.E., Sacred Terror: Religion and Horror on the Silver Screen, Baylor University Press, Waco 2008.

Creed B., The Monstrous-Feminine: Film, Feminism, Psychoanalysis, Routledge, London-New York 2007.

Hamilakis Y., Pluciennik M., Tarlow S., Thinking through the Body: Archaeologies of Corporeality, Kluwer Academic, New York 2002.

Hatty S.E., Hatty J., The Disordered Body: Epidemic Disease and Cultural Transformation, State University of New York, Albany 1999.

Kristeva J., Powers of Horrors: An Essay on Abjection, Columbia University Press, New York 1982. Metcalf P., Huntington R., Celebrations of Death: The Anthropology of Mortuary Ritual, Cambridge University Press, New York 1991.

Morgan J., The Biology of Horror: Gothic Literature and Film, Southern Illinois University Press, Carbondale 2002.

Roiphe K., The Morning After: Sex, Fear, and Feminism, Little, Brown and Co., London 1993.

\section{Thanatomorphose and Contracted: Feminine body and sexuality in horror and the horror of feminine body and sexuality}

Summary

The paper juxtaposes two films - Thanatomorphose directed by Éric Falardeau (2012) and Contracted directed by Eric England (2013) - in order to illustrate how both use similar themes of rot, disfigurement and decay of the body to paint different images of the female body and its aesthetic and functional value. Through the use of close reading, the analysis focuses on the manner in which the aforementioned themes in the discussed film texts are expressed within the boundaries of horror discourse to emphasize issues such as abuse, objectification and self-harm.

${ }^{25}$ S.E. Hatty, J. Hatty, op. cit., p. 24. 